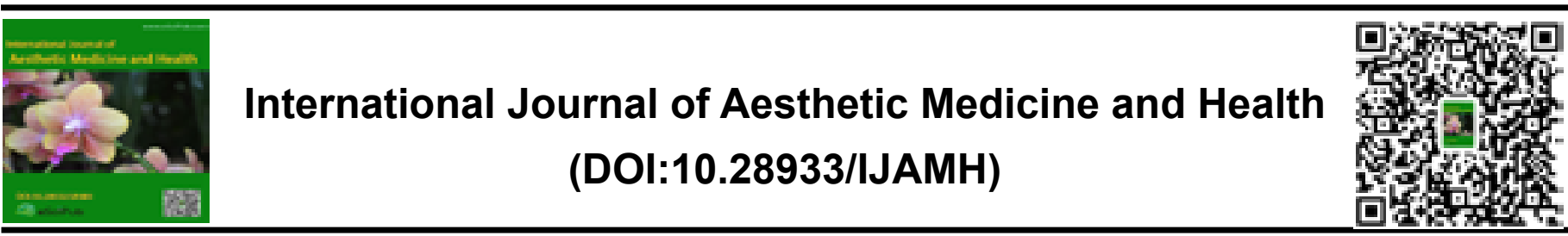

\title{
EXPERIENCE REPORT: PUBLIC ATTENDANCE WITH ANAMNESIS, BIOIMPED ASSESSMENT AND BASIC SKIN CLEANING PROTOCOL SERVICES
}

\author{
Teixeira, vitória Carreiro de França'; MEDEIROS, Laura Guimaro Cunha de²; MIZOBATA, \\ Nathalia Ayako Mitsueda ${ }^{3}$
}

${ }^{1}$ Federal University of Goiás ${ }^{2}$ Federal University of Goiás ${ }^{3}$ Federal University of Goiás ABSTRACT

Introduction: Concern about beauty is noticeably growing in our society. Thus, aesthetics are used to meet the search needs not only for physical well-being, but also for biopsychosocial. Skin care is essential for maintaining its vitality. Therefore, daily treatment is indispensable to establish skin balance, controlling hydration, oiliness and protection against ultraviolet rays. The importance of teaching people how to take care of their skin is essential to the quality of life, however there are still myths and conflicts to be fought about preventive care. Thereby, it helps to strengthen the construction of positive self-image, as well as collaboration to improve the quality of life, encompassing mental, physical and psychological health of the individual. Objectives: To provide participants with basic knowledge of daily facial skin care, guiding the correct order of the products to be used, prevention methods against photoaging, epidermal intoxication, oiliness and dehydration. Provide practical and explanatory demonstration on the subject, and demonstrate physiological patterns of hydration and oiliness of the patient's skin through bioimpedance. Methodology: At first, an anamnesis form was made to evaluate the community skin routine. Factors such as age, ethnicity, history and habits were considered relevant in the condition of a skin. Then instructions were given and questions about the correct skin cleansing protocol were solved. Participants also underwent an assessment of the proportion of the amount of oil and water on their faces, made from a digital bioelectrical impedance device. Finally, the skin was cleaned following the steps of: cleaning, exfoliation, toning, moisturizing and use of sunscreen. Results: A total of 42 people were attended with the anamnesis and simple skin cleansing service, 34 female and 8 male, aged between 9 and 55 years. The data obtained with the questionnaire sheet showed that there are varied patterns of self-care regarding the skin, highlighting the greater attention of women than men, which indicates social factors associated with the behavior and routine evaluated. In addition, several wrong practices in skin care have been found, so that although the individual has the information of what would be correct, bad habits persist in the population. Conclusion: The results of the procedures were satisfactory, and in the majority after skin cleansing there was a balance in the water/oil ratio of the face. In addition, there was a need to reinforce correct skin care so that they could reproduce these processes practically and correctly in their daily lives.
Keywords: anamnesis, health, self-image and aesthetics.

*Correspondence to Author: Teixeira, vitória Carreiro de França Federal University of Goiás

How to cite this article:

Teixeira, vitória Carreiro de França; MEDEIROS, Laura Guimaro Cunha de; MIZOBATA, Nathalia Ayako Mitsueda.EXPERIENCE REPORT: PUBLIC ATTENDANCE WITH ANAMNESIS, BIOIMPED ASSESSMENT AND BASIC SKIN CLEANING PROTOCOL SERVICE. International Journal of Aesthetic Medicine and Health, 2020, 3:6

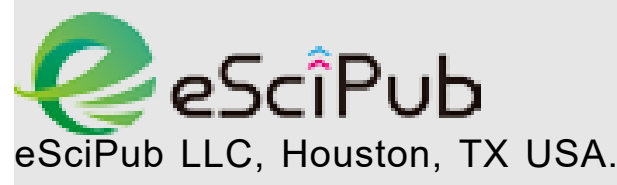

Website: https://escipub.com/ 